\title{
Chaperones and intimate physical examinations: what do male and female patients want?
}

\author{
VC Fan, HT Choy, George YJ Kwok, HG Lam, QY Lim, YY Man, CK Tang, CC Wong, YF Yu, \\ Gilberto KK Leung *
}

\section{A B S T R A C T}

Introduction: Many studies of patients' perception of a medical chaperone have focused on female patients; that of male patients are less well studied. Moreover, previous studies were largely based on patient populations in English-speaking countries. Therefore, this study was conducted to investigate the perception and attitude of male and female Chinese patients to the presence of a chaperone during an intimate physical examination.

Methods: A cross-sectional guided questionnaire survey was conducted on a convenient sample of 150 patients at a public teaching hospital in Hong Kong.

Results: Over $90 \%$ of the participants considered the presence of a chaperone appropriate during intimate physical examination, and $84 \%$ felt that doctors, irrespective of gender, should always request the presence of a chaperone. The most commonly cited reasons included the availability of an objective account should any legal issue arise, protection against sexual harassment, and to provide psychological support. This contrasted with the experience of those who had previously undergone an intimate physical examination of whom only $72.6 \%$ of women and $35.7 \%$ of men had reportedly been chaperoned. Among female participants, $75.0 \%$ preferred to be chaperoned during an

This article was published on 2 Dec 2016 at www.hkmj.org. intimate physical examination by a male doctor, and $28.6 \%$ would still prefer to be chaperoned when being examined by a female doctor. Among

male participants, over $50 \%$ indicated no specific preference but a substantial minority reported a preference for chaperoned examination (21.2\% for male doctor and $25.8 \%$ for female doctor).

Conclusions: Patients in Hong Kong have a high degree of acceptance and expectations about the role of a medical chaperone. Both female and male patients prefer such practice regardless of physician gender. Doctors are strongly encouraged to discuss the issue openly with their patients before they conduct any intimate physical examination.

\begin{tabular}{l} 
Hong Kong Med J 2017;23:35-40 \\
\hline DOI: 10.12809/hkmj164899 \\
${ }^{1}$ VC Fan, BSc \\
${ }^{1}$ HT Choy, BSc \\
${ }^{1}$ GY Kwok \\
${ }^{1}$ HG Lam \\
${ }^{1}$ QY Lim \\
${ }^{1}$ YY Man \\
${ }^{1}$ CK Tang \\
${ }^{1}$ CC Wong \\
${ }^{1}$ YF Yu \\
${ }^{2}$ GKK Leung *, MB, BS, PhD \\
${ }^{1}$ Department of Community Medicine \\
${ }^{2}$ Department of Surgery \\
Li Ka Shing Faculty of Medicine, The University of Hong Kong, Pokfulam, \\
Hong Kong \\
* Corresponding author: gilberto@hku.hk
\end{tabular}

\section{New knowledge added by this study}

- Hong Kong patients have a high degree of acceptance and expectations about the presence of a medical chaperone during an intimate physical examination (IPE), but in actual practice, females and especially male patients are chaperoned less often than they would have preferred.

- A substantial minority (21\%-29\%) of Hong Kong patients of both genders preferred to be chaperoned for an IPE even when examined by a doctor of the same gender.

- More than a quarter (26\%) of male patients preferred to be chaperoned for an IPE when examined by a female doctor.

Implications for clinical practice or policy

Before any IPE, regardless of doctor or patient gender, it is advisable for doctors to ask their patients if they would like to be chaperoned in order to respect for patient preferences.

\section{Introduction}

In this current era when personal privacy is highly regarded, it may seem counterintuitive for patients to prefer the presence of a third party during an intimate physical examination (IPE). The presence of a medical chaperone, however, may offer comfort and psychological support for patients in protecting them against indecent behaviour, and is 


\section{見證人與毫涉敏感部位的身體檢查: 男性和女性 病人的選擇

\author{
范偉銓、蔡曉婷、郭原禎、林瀚剛、林沁穎、文欣欣、 \\ 鄧子健、黃卓卓、余義鋒、梁嘉傑
}

引言：過往有不少關於女性病人對醫療見證人認知的研究, 從男性患 者角度探討的文獻相對較少, 而且主要在英語國家進行。因此, 本研 究旨在探討華籍男女病人在進行牽涉敏感部位的身體檢查過程中對於 醫療見證人的感知和態度

方法：於香港一所公立醫院進行簡便抽樣的橫斷式問卷調查。

結果：超過九成被訪者認為進行牽涉敏感部位的身體檢查時有見證人 在場是一個恰當的安排。 $84 \%$ 的被訪者認為不論是男醫生或女醫生, 都應該在為病人檢查時詢問他們是否需要有見證人在場, 原因包括見 證人可以在檢查過程中出現懷疑不當行為時提供證詞、令病人減低 受到性騷擾的風險, 以及為病人提供心理上的支持。然而, 在曾經 接受敏感部位檢查的參與者當中, 只有 $72.6 \%$ 的女士和 $35.7 \%$ 的男士 表示當時有見證人在場。 $75.0 \%$ 的女性被訪者希望在被男醫生檢查時 有見證人在場。另外有 $28.6 \%$ 的女士希望在被女醫生檢查時也有見證 人在場。超過 $50 \%$ 的男性被訪者對檢查時有否見證人在場表示無既定 取向, 但仍然有相當一部分男性被訪者希望有見證人在場（男醫生為 $21.2 \%$ ，女醫生為 $25.8 \%$ ）

結論：香港大多數病人願意接受在身體檢查時有見證人在場。不論醫 生性別, 男女病人都希望有見證人在場。因此, 醫生應該在檢查病人 敏感部位前先了解他們是否想要有見證人在場的意願。 now an established good practice. ${ }^{1}$ Conversely, in an increasingly litigious society, a chaperone may serve as a witness to protect doctors against false allegations. ${ }^{2}$ Usually IPEs involve per-rectal, genital, or breast examinations, but may also include physical contact with any other part of the patient's body.

The majority of reports about patients perceptions of a medical chaperone have focused on female patients ${ }^{3-7}$; those of male patients are less well studied. ${ }^{8-10}$ A potential discrepancy may exist between the two groups. Santen et $\mathrm{al}^{10}$ reported that in the US, a great majority of male patients (88\%) did not care about the presence of a chaperone, while half of the female patients would prefer to be chaperoned when examined by a male physician, and a quarter when examined by a female doctor. Moreover, previous studies have been largely based on patient populations in English-speaking countries. It has been suggested that the presence of a chaperone is a 'western concept' that may receive a different degree of emphasis or acceptance in other parts of the world. ${ }^{11}$ To the best of our knowledge, there has been no related report on patients in Hong Kong. In this study, we investigated patients' attitudes towards and experiences with the presence of a medical chaperone, and in particular, the relevant impact of patient and physician gender.

\section{Methods}

\section{Study design}

We conducted a cross-sectional questionnaire survey of patients waiting for their consultations at the Accident and Emergency Department and the surgical out-patient clinic of a public teaching hospital over a period of 2 weeks from late February to early March 2015. Participants were recruited irrespective of age, gender or ethnicity, but were excluded if they were under 18 years of age, or did not understand English, Cantonese, or Mandarin. Participants from the surgical out-patient clinic included both new and follow-up patients from various subspecialties. Informed patient consent and approval from the Institutional Review Board of our institution were obtained.

\section{Survey instrument}

The questionnaire, written in both English and Chinese, comprised eight questions on demographics, and 19 questions on previous experiences with IPE, preferences for the presence of a chaperone, influence of gender of the examining physician, and the underlying reasons for their preferences. Participants selected their answers from predetermined options. In this study, IPE was defined as breast, pelvic, genital, and/or per-rectal examination. This was explained to the participants at the beginning of the survey. Guidance on the survey was provided by an investigator if requested by the participant.

\section{Statistical analyses}

Data were analysed using the Statistical Package for the Social Sciences (Windows version 22.0; SPSS Inc, Chicago [IL], US). Descriptive analyses were performed on demographic data and participant responses. Patient ages were grouped into age ranges $(<40,40-59$, and $\geq 60)$ for analysis. The independent variables were patient gender and other demographic variables (eg age, education level). The dependent variables were preference for the examining doctor's gender, presence of a chaperone with a male examining doctor, gender of chaperone with a male examining doctor, presence of chaperone with a female examining doctor, and gender of chaperone with a female examining doctor. Bivariate analyses using the Chi squared test were performed to compare the various independent variables against the dependent variables. Other variables based on participant responses-such as reasons behind chaperone preferences, previous experience of IPE, and tendency for litigation if felt harassed-were analysed against other variables as appropriate. Statistical significance was set at a probability level of 0.05 . 


\section{Results}

\section{Participant profile and demographics}

Of a convenience sample of 183 patients, 33 declined to participate and 150 patients were recruited. Of these patients, 83 (55.3\%) were from the Accident and Emergency Department and 67 (44.7\%) were from surgical out-patient clinics. Recruitment was done in both locations during the mornings or afternoons of 23, 24 and 26 February, and 2 and 6 March 2015.

There were similar numbers of women $(56.0 \%)$ and men (44.0\%). Their mean age was 50 (range, 18-87) years. The majority (75.3\%) had completed a secondary or higher level of education. Over half (53.3\%) were non-religious, and approximately $40 \%$ were retired. The majority of men $(63.6 \%, 42 / 66)$ and women $(71.4 \%, 60 / 84)$ were married. Almost all participants $(98.0 \%, \mathrm{n}=147)$ declared themselves as heterosexual (Table 1).

\section{Perception of intimate physical examination and preference for physician gender}

In addition to our definitions of IPE, significantly more women than men also found chest examination of the respiratory system to be intimate $(44.0 \%$, $37 / 84$ women vs $13.6 \%, 9 / 66$ men; $\mathrm{P}<0.01)$. Among the entire sample, upper limb, lower limb, and abdominal examinations were also considered to be intimate by five (3.3\%), 14 (9.3\%), and 19 (12.7\%) participants, respectively. Overall, 42 (50.0\%) women preferred a female doctor for IPE; only one (1.2\%) preferred a male doctor (Table 2). The only significant determining factor for women preferring a female doctor for IPE was the absence of prior experience of IPE $(\mathrm{P}=0.04)$; notable but nonsignificant determining factors included younger age $(\mathrm{P}=0.09)$ and being unmarried $(\mathrm{P}=0.10)$. For men, 42 (63.6\%) participants did not have any preference for physician gender and 21 (31.8\%) would prefer a male doctor (Table 2). No significant determining factors for men preferring either a male or female doctor for IPE were identified.

\section{Previous experiences of intimate physical examination and general preferences for chaperoned examination}

Of the 150 participants, 115 (76.7\%) reported previous experience of IPE: 42 were men $(63.6 \%$ of male participants) and 73 were women $(86.9 \%$ of female participants). A large majority (90.7\%, $136 / 150)$ of the participants considered the presence of a chaperone appropriate during IPE, and $84.0 \%(126 / 150)$ felt that doctors, irrespective of gender, should always ask if the patient would like a chaperone. This contrasted with the experience of those who had had previous IPE of whom only $72.6 \%(53 / 73)$ of women and $35.7 \%(15 / 42)$ of men
TABLE I. Demographic data of participants $(n=150)$

\begin{tabular}{|c|c|}
\hline Demographics & $\begin{array}{c}\text { No. }(\%) \text { of } \\
\text { participants* }\end{array}$ \\
\hline \multicolumn{2}{|l|}{ Gender } \\
\hline Male & $66(44.0)$ \\
\hline Female & $84(56.0)$ \\
\hline Mean (range) age (years) & $50(18-87)$ \\
\hline \multicolumn{2}{|l|}{ Highest level of education } \\
\hline No schooling / pre-primary & $10(6.7)$ \\
\hline Primary school & $27(18.0)$ \\
\hline Secondary school & $65(43.3)$ \\
\hline $\begin{array}{l}\text { Post-secondary (diploma, certificate, } \\
\text { subdegree, degree) }\end{array}$ & $41(27.3)$ \\
\hline Postgraduate & $7(4.7)$ \\
\hline \multicolumn{2}{|l|}{ Monthly household income (HK\$) } \\
\hline$<5000$ & $66(44.0)$ \\
\hline $5000-10000$ & $17(11.3)$ \\
\hline $10001-20000$ & $41(27.3)$ \\
\hline $20001-40000$ & $18(12.0)$ \\
\hline$>40000$ & $8(5.3)$ \\
\hline \multicolumn{2}{|l|}{ Religion } \\
\hline Christian (Protestant) & $20(13.3)$ \\
\hline Christian (Catholic) & $12(8.0)$ \\
\hline Buddhist & $26(17.3)$ \\
\hline Other religion & $12(8.0)$ \\
\hline No religion & $80(53.3)$ \\
\hline \multicolumn{2}{|l|}{ Occupation } \\
\hline Manager or administrator & $7(4.7)$ \\
\hline Craft and related trades worker & $7(4.7)$ \\
\hline Professional & $15(10.0)$ \\
\hline Labourer & $8(5.3)$ \\
\hline Clerk & $12(8.0)$ \\
\hline Student & $10(6.7)$ \\
\hline Service industry or sales worker & $16(10.7)$ \\
\hline Housewife & $18(12.0)$ \\
\hline Retired & $57(38.0)$ \\
\hline \multicolumn{2}{|l|}{ Marital status } \\
\hline Single & $48(32.0)$ \\
\hline Married & $102(68.0)$ \\
\hline \multicolumn{2}{|l|}{ Sexual orientation } \\
\hline Heterosexual & $147(98.0)$ \\
\hline Others & $3(2.0)$ \\
\hline
\end{tabular}

* Except otherwise stated

reported having been chaperoned. For those whose previous IPE was unchaperoned, $75.0 \%(15 / 20)$ of women and $44.4 \%(12 / 27)$ of men would actually prefer to be chaperoned. Interestingly, participants with prior experience of IPE, irrespective of gender, 
TABLE 2. Participants' preferences for physician gender and the presence of a chaperone during intimate physical examination

\begin{tabular}{|c|c|c|c|}
\hline \multirow[t]{2}{*}{ Participant's preference } & \multicolumn{3}{|c|}{ Subject gender } \\
\hline & $\begin{array}{l}\text { Male (\% within } \\
\text { subject gender) }\end{array}$ & $\begin{array}{l}\text { Female (\% within } \\
\text { subject gender) }\end{array}$ & $\begin{array}{l}\text { Total (\% within } \\
\text { subject gender) }\end{array}$ \\
\hline \multicolumn{4}{|c|}{ Preference for doctor gender for intimate physical examination } \\
\hline Male & $21(31.8)$ & $1(1.2)$ & $22(14.7)$ \\
\hline Female & $3(4.5)$ & $42(50.0)$ & $45(30.0)$ \\
\hline No preference & $42(63.6)$ & $41(48.8)$ & 83 (55.3) \\
\hline Total & $66(100)$ & $84(100)$ & $150(100)$ \\
\hline \multicolumn{4}{|c|}{ Preference for presence of a chaperone if the examining doctor is male } \\
\hline Yes & $14(21.2)$ & $63(75.0)$ & 77 (51.3) \\
\hline No & $18(27.3)$ & $4(4.8)$ & $22(14.7)$ \\
\hline No preference & $34(51.5)$ & $17(20.2)$ & $51(34.0)$ \\
\hline Total & $66(100)$ & $84(100)$ & $150(100)$ \\
\hline \multicolumn{4}{|c|}{ Preference for chaperone gender if the examining doctor is male } \\
\hline Male & $9(26.5)$ & $3(4.3)$ & $12(11.7)$ \\
\hline Female & $4(11.8)$ & $55(79.7)$ & $59(57.3)$ \\
\hline No preference & $21(61.8)$ & $11(15.9)$ & $32(31.1)$ \\
\hline Total & $34(100)$ & $69(100)$ & $103(100)$ \\
\hline \multicolumn{4}{|c|}{ Preference for presence of a chaperone if the examining doctor is female } \\
\hline Yes & $17(25.8)$ & $24(28.6)$ & $41(27.3)$ \\
\hline No & $13(19.7)$ & $31(36.9)$ & $44(29.3)$ \\
\hline No preference & $36(54.5)$ & $29(34.5)$ & 65 (43.3) \\
\hline Total & $66(100)$ & $84(100)$ & $150(100)$ \\
\hline \multicolumn{4}{|c|}{ Preference for chaperone gender if the examining doctor is female } \\
\hline Male & $11(34.4)$ & $0(0)$ & $11(14.7)$ \\
\hline Female & $1(3.1)$ & $36(83.7)$ & $37(49.3)$ \\
\hline No preference & $20(62.5)$ & 7 (16.3) & $27(36.0)$ \\
\hline Total & $32(100)$ & $43(100)$ & 75 (100) \\
\hline
\end{tabular}

were significantly more likely to want a chaperone when examined by a male doctor $(57.4 \%$ with vs $28.6 \%$ without; $\mathrm{P}<0.01)$ but not a female doctor (28.7\% with vs $25.7 \%$ without; $\mathrm{P}=0.87$ ) when compared with those with no such experience. Most participants $(72.7 \%, 109 / 150)$ regarded health care workers as suitable chaperones, and 52.7\% (79/150) would also consider a family member, and $20.0 \%$ (30/150) a friend to be appropriate.

The most commonly cited reasons for preferring a chaperone included the availability of an objective account should any legal issue arise (61.3\%, 92/150), protection against sexual harassment by the doctor $(48.0 \%, 72 / 150)$, and psychological support $(43.3 \%, 65 / 150)$ [Fig a]. The most commonly cited reasons for not having a chaperone included embarrassment (34.7\%, 52/150); significantly more men $(43.9 \%, 29 / 66)$ than women $(27.4 \%, 23 / 84)$ considered a chaperone's presence embarrassing
$(\mathrm{P}=0.03)$. Furthermore, $26.0 \%$ of the participants $(39 / 150)$ felt that the presence of a chaperone would undermine their privacy (Fig b).

\section{Women's preferences for chaperoned intimate physical examination}

The majority of women $(75.0 \%, 63 / 84)$ would prefer a chaperone to be present when being examined by a male doctor, and $79.7 \%(55 / 69)$ of female respondents preferred that chaperone to be female (Table 2). Even when being examined by a female doctor, $28.6 \%(24 / 84)$ would still prefer to be chaperoned (Table 2). Women aged between 40 and 59 years were significantly more likely than other age-groups to prefer chaperoned IPE when examined by a female doctor $(\mathrm{P}=0.04)$. Other demographic factors-including education level, income, religion and marital status-were not significantly associated with any particular preferences. 


\section{Men's preferences for chaperoned intimate physical examination}

More than half of the men had no specific preference, regardless of physician gender. There was, however, a proportion who would want to be chaperoned when examined by a male $(21.2 \%, 14 / 66)$ or female $(25.8 \%, 17 / 66)$ doctor (Table 2). Men who wished to be chaperoned when examined by a male doctor were significantly more likely to also prefer being chaperoned when examined by a female doctor $(\mathrm{P}<0.01)$. Of note is that a great majority of the men who preferred chaperoned IPE when examined by a male doctor indicated that chaperones could provide an objective account should a legal issue arise $(85.7 \%, 12 / 14)$. There were no significant differences in terms of demographic variables between the 'no preference,' 'no chaperone', and 'prefer chaperone' groups, regardless of the examining doctor's gender.

\section{Discussion}

Our results highlighted the different views of male and female subjects in this locality. The majority of our female patients would prefer to be chaperoned when examined by a male doctor, and previous experience of IPE appeared to enforce such a tendency. This finding is consistent with those from other countries, ${ }^{4,8,12}$ Interestingly, and somewhat unexpectedly, a substantial minority of women would still prefer to be chaperoned when examined by a female doctor. Another noteworthy finding was that male participants who preferred a chaperoned IPE by a male doctor would also hold a similar preference when examined by a female doctor, and that their most commonly cited reason was the availability of an objective account in case of medicolegal disputes. This was despite concerns about personal privacy and feelings of embarrassment.

Our findings compare well with the situation in the United Kingdom ${ }^{13}$ and Australia ${ }^{14}$ where the majority of patients were aware of and would prefer the practice. When compared with a similar study conducted at the Emergency Department in the US, however, we found that patients in Hong Kong were more likely to prefer chaperoned IPE when examined by a doctor of the opposite sex (male patient-female doctor: $25.8 \%$ vs $2-3 \%$; female patient-male doctor: $75 \%$ vs $45-47 \%){ }^{3}$ Other studies found that physician gender had a variable impact on female patient's preference for a chaperone. ${ }^{10}$ Our findings suggest a generally higher degree of acceptance of, if not expectation for, the presence of a medical chaperone in Hong Kong, although differences in study setting, subject profile, and study definitions of IPE limit the validity of such comparisons.

The reported experiences of participants who have had previous IPE indicate that their expectations have not been met on a number of occasions. Several

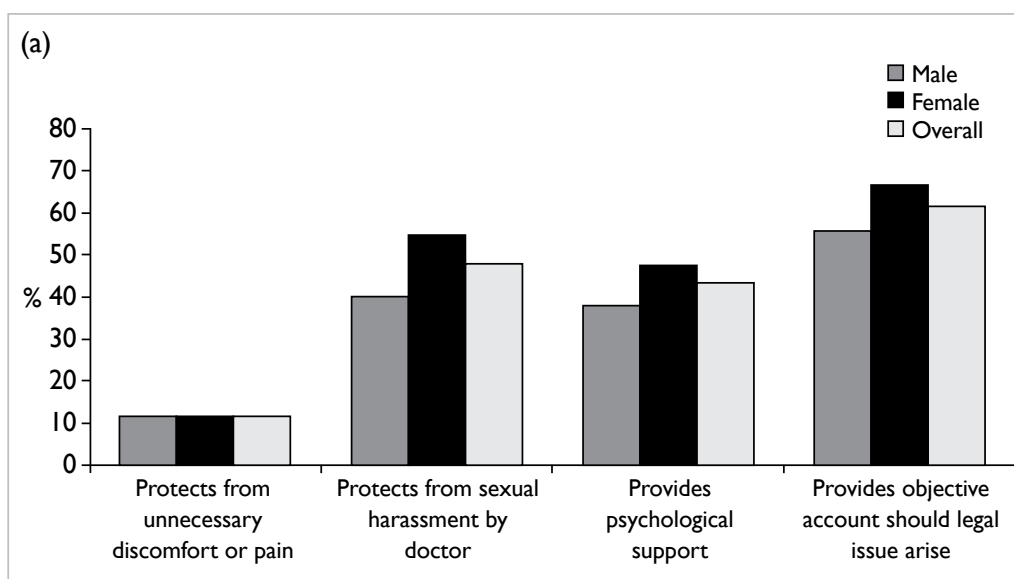

(b)

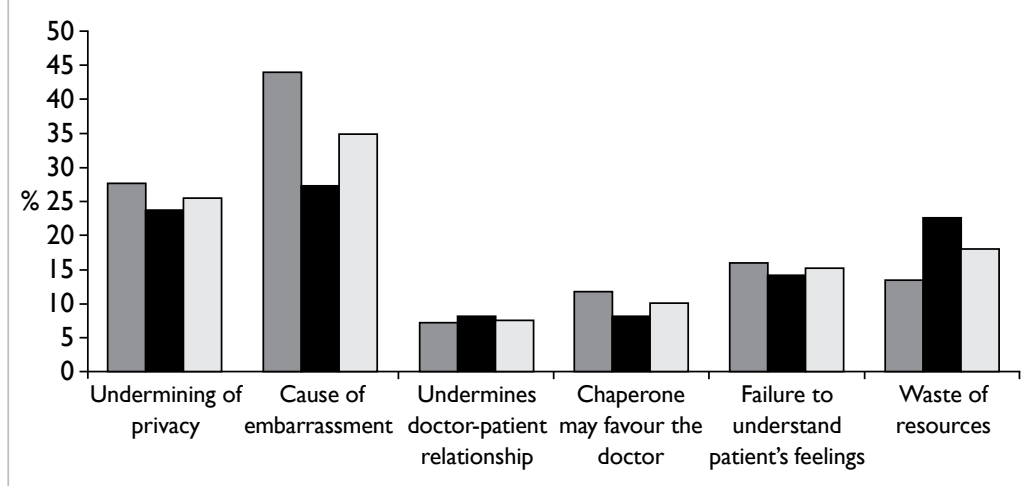

FIG. Reasons (a) for and (b) against the presence of a chaperone during intimate physical examination

reasons have been suggested for the inadequate use of chaperones including, inter alia, the shortage of nursing staff to act as chaperones, ${ }^{15}$ and a general lack of awareness. ${ }^{16}$ This is certainly an area for improvement in our health care setting. In this regard, it is important to note that some patients would also consider examinations of the abdomen and limbs to be intimate, and that chaperones may still be preferred even when the physician and patient are of the same gender. The Code of Professional Conduct issued by the Medical Council of Hong Kong states that 'an intimate examination of a patient is recommended to be conducted in the presence of a chaperone to the knowledge of the patient. ${ }^{17}$ 'Intimate examination' is not defined and there is no advice about the impact of gender. The United Kingdom General Medical Council (GMC) guidelines nonetheless specify that IPE may include 'any examination where it is necessary to touch or even be close to the patient', and the requirement for a chaperone should apply whether or not the patient and doctor are of the same or opposite gender. ${ }^{1}$ Challenging situations may arise when there is a shortage of staff or when the patient refuses the 
presence of a chaperone. The GMC have provided some detailed guidance. ${ }^{1}$

Our study has several limitations. First, the number of participants was relatively small and our findings may not be readily generalisable, particularly outside the public hospital setting, where patients are likely to be more familiar with their doctor and have more control over which doctor sees and examines them. The convenient sampling method that we adopted may result in systematic bias, skewed results, and potentially suboptimal generalisability of our findings. Second, our definition of IPE encompassed a range of different examinations, and it might be possible that participants have different preferences regarding each type. Third, our cohort consisted of relatively few young subjects (only 15\% were aged $<30$ years) and this might have affected our ability to demonstrate any impact of age. Last, as to the reasons for participants' preferences, our questionnaire only provided a short list of options rather than an open question and this could have limited the range of responses. Future studies may focus on patient's preferences in specific settings (eg primary care) as well as physician's practice in order to inform and promote public and professional awareness in Hong Kong.

\section{Conclusions}

Patients in Hong Kong have a high degree of acceptance towards the presence of a medical chaperone. Both female and male patients prefer such practice regardless of physician gender although individual patients may value the practice differently. Doctors are strongly encouraged to discuss the issue openly with their patients and offer the presence of a chaperone prior to any IPE; an alternative would be to put up a sign asking patients to notify the doctor or other staff if they prefer the presence of a chaperone during IPE.

\section{Declaration}

All authors have disclosed no conflicts of interest.

\section{References}

1. General Medical Council. Good medical practice (2013). Available from: http://www.gmc-uk.org/guidance/good_ medical_practice.asp. Accessed 27 Nov 2015.
2. Wai D, Katsaris M, Singhal R. Chaperones: are we protecting patients? Br J Gen Pract 2008;58:54-7.

3. Buchta RM. Adolescent females' preferences regarding use of a chaperone during a pelvic examination. Observations from a private-practice setting. J Adolesc Health Care 1986;7:409-11.

4. Patton DD, Bodtke S, Homer RD. Patient perceptions of the need for chaperones during pelvic exams. Fam Med 1990;22:215-8.

5. Fiddes P, Scott A, Fletcher J, Glasier A. Attitudes towards pelvic examination and chaperones: a questionnaire survey of patients and providers. Contraception 2003;67:313-7.

6. Simanjuntak C, Cummings R, Chen MY, Williams H, Snow A, Fairley CK. What female patients feel about the offer of a chaperone by a male sexual health practitioner. Int J STD AIDS 2009;20:165-7.

7. Sinha S, De A, Jones N, Jones M, Williams RJ, VaughanWilliams E. Patients' attitude towards the use of a chaperone in breast examination. Ann R Coll Surg Engl 2009;91:46-9.

8. Penn MA, Bourguet CC. Patients' attitudes regarding chaperones during physical examinations. J Fam Pract 1992;35:639-43.

9. Osmond MK, Copas AJ, Newey C, Edwards SG, Jungmann E, Mercey D. The use of chaperones for intimate examinations: the patient perspective based on an anonymous questionnaire. Int J STD AIDS 2007;18:667-71.

10. Santen SA, Seth N, Hemphill RR, Wrenn KD. Chaperones for rectal and genital examinations in the emergency department: what do patients and physicians want? South Med J 2008;101:24-8.

11. Van Hecke O, Jones $\mathrm{K}$. The use of chaperones in general practice: Is this just a 'Western' concept? Med Sci Law 2015;55:278-83.

12. Teague R, Newton D, Fairley CK, et al. The differing views of male and female patients toward chaperones for genital examinations in a sexual health setting. Sex Transm Dis 2007;34:1004-7.

13. Pydah KL, Howard J. The awareness and use of chaperones by patients in an English general practice. J Med Ethics 2010;36:512-3.

14. Baber JA, Davies SC, Dayan LS. An extra pair of eyes: do patients want a chaperone when having an anogenital examination? Sex Health 2007;4:89-93.

15. Price DH, Tracy CS, Upshur RE. Chaperone use during intimate examinations in primary care: postal survey of family physicians. BMC Fam Pract 2005;6:52.

16. Vogel L. Chaperones: friend or foe, and to whom? CMAJ 2012;184:642-3.

17. Medical Council of Hong Kong. Code of Professional Conduct. 2009. Available from: http://www.mchk.org.hk/ Code_of_Professional_Conduct_2009.pdf. Accessed 30 Aug 2015. 